\title{
Criando Jogos Digitais para a aprendizagem de matemática no ensino fundamental I
}

\author{
Cintia Shimohara $^{1}$ e Elaine Silva Rocha Sobreira ${ }^{2}$ \\ ${ }^{1}$ Professora de Matemática - Centro Educacional Pioneiro - São Paulo - SP - Brasil \\ ${ }^{2}$ Tecnologia Educacional - Centro Educacional Pioneiro - São Paulo - SP - Brasil e \\ Mestranda em ensino de ciências e matemática - Unicamp - Campinas - SP - Brasil. \\ cintia@pioneiro.g12.br, elaine@pioneiro.g12.br
}

\begin{abstract}
There is a current discussion, and also a reflection upon the usage of games integrated to curricular contents, putting together the attractiveness of the games and the learning process. Considering the new ways of thinking the integration of technologies not only as consumers, but also as producers, some practices of games productions are being developed in order to expand the students' potential creativity to produce technology. This article describes what was developed in 2015 at one educational institute, with 4 groups of 5th grade students, from elementary school. They developed digital games with math challenges, using the motivational and engaging potential of games with the creation of math challenges.
\end{abstract}

Resumo. Atualmente há uma reflexão e discussão sobre o uso de jogos integrados ao conteúdo curricular, aliando a ludicidade daqueles à aprendizagem. Com as novas formas de pensar a integração das tecnologias para um uso de criação e não apenas de consumo, práticas de produção de jogos estão sendo desenvolvidas a fim de expandir o potencial criativo dos alunos para a produção de tecnologias. Este artigo descreve o trabalho desenvolvido no ano de 2015 em uma instituição escolar, com 4 turmas do $5^{\circ}$ ano do ensino fundamental I, cujos alunos desenvolveram jogos digitais com desafios de matemática, aliando o poder motivador dos jogos à criação de desafios.

\section{Introdução}

Na educação, já é consenso a importância da integração dos recursos tecnológicos, no entanto ainda se discute como integrar essas tecnologias ao currículo em uma abordagem que não reproduza práticas educacionais que podem ser aplicadas sem a necessidade da utilização de tecnologias, mas sim, que vá ao encontro dos desafios e necessidades dos cidadãos que atuam na sociedade do século XXI.

Costa (2007), chama a atenção para a necessidade, de acordo com perspectivas mais recentes sobre aprendizagem, de se desenvolver estratégias para trabalhar com as tecnologias em consonância com uma "aprendizagem de qualidade, profunda e significativa". Ressalta também que a utilização dos computadores na educação ainda não 
corresponde às expectativas de transformação da escola, refletindo o modo como se realiza a inclusão dos computadores no currículo, deixando de oferecer a oportunidade para que os alunos possam aprender de forma diferenciada, sem uma continuidade do ensino tradicional.

A atual geração de alunos já faz uso das mais diversas tecnologias no cotidiano e na vida em sociedade. Por isso, o papel de inclusão digital na escola vem se modificando, deixando de oferecer um simples acesso, para oferecer a oportunidade de uma utilização que ultrapasse o simples consumo de tecnologias. Mota e colaboradores (2014) chama a atenção para um uso dos recursos computacionais que vão além da realização de atividades rotineiras, incluindo o desenvolvimento de novos programas com diferentes funcionalidades e envolvendo conhecimentos de lógica de programação. Diante dessa constatação, fica clara a necessidade de os alunos saberem para além das diferentes tecnologias; eles precisarão, para isso, saber criar com elas, ou seja, precisarão entender os códigos computacionais, deixando de ser meros consumidores e passando a desenvolver habilidades para criar, produzir, escrever e compartilhar com as tecnologias, disseminando conhecimentos.

Nesse contexto, os jogos digitais estão sendo utilizados na educação, tanto como recursos que aliam a ludicidade a um potencial educativo (Andrade, et. all, 2013) quanto como criação e produção autoral através da programação de jogos.

Analisando relatos dos congressos WIE e SBGames, verificamos que estão sendo divulgadas práticas que integram a programação ao conteúdo curricular, seja na criação de jogos ou de outros recursos como animação ou recursos interativos. Estas práticas, em sua maioria, são realizadas com alunos do ensino fundamental II ou ensino médio, como vemos nos relatos de Andrade e colaboradores (2013), que desenvolveram um jogo digital de matemática com alunos do $9^{\circ}$ ano do Ensino Fundamental. Outra experiência é relatada por Gomes e colaboradores (2014) sobre o uso de programação nas aulas de química, física e matemática através da produção de animações e documentos interativos relacionados ao conteúdo curricular, trazendo valiosas contribuições para o estudo do uso da programação aliada ao currículo escolar.

No caso deste artigo, relatamos a experiência de um trabalho colaborativo, desenvolvido com alunos do $5^{\circ}$ ano do ensino fundamental I, do Centro Educacional Pioneiro - SP. Nesse trabalho, os alunos utilizaram-se do conteúdo de matemática, que estava sendo desenvolvido no decorrer do primeiro trimestre, para criar desafios de matemática que fariam parte dos jogos digitais. Este processo criativo e autoral permitiu o desenvolvimento de habilidades próprias do trabalho de programação, favorecidas pelo uso do Scratch. Nesse contexto, as novas tecnologias foram integradas ao currículo escolar numa perspectiva de criação e autoria, no qual os alunos foram os protagonistas de sua própria aprendizagem.

A estrutura deste artigo está organizada da seguinte maneira: no item 2, discutiremos o ensino de programação para o desenvolvimento de habilidades e a sua integração com a matemática na resolução de problemas. No item 3 abordaremos o uso do Scratch para o desenvolvimento de jogos digitais, enquanto no item 4 será descrito o trabalho de criação de jogos digitais envolvendo a produção de situações problemas relacionados ao conteúdo curricular de matemática. Para finalizar, nos itens 5 e 6 apresentaremos os resultados, conclusões e necessidade de continuidade do trabalho. 


\section{O ensino de programação e a matemática}

O trabalho com programação na educação básica iniciou-se na década de 60 com o educador Seymour Papert, através da linguagem Logo, buscando desenvolver uma relação de interação entre o aluno e o computador, através de uma abordagem denominada construcionismo, a qual permite aos alunos uma aprendizagem por descobertas, em que o erro é visto como uma forma de testar e rever o processo percorrido.

Trabalhar com programação no ensino fundamental I, exige a utilização de programas apropriados que sejam de fácil compreensão e intuitivo para as crianças. Diante dessas exigências, o Scratch, criado por Mitchel Resnick (responsável pelo grupo Lifelong Kindergarten do Laboratório de Mídia no Instituto de Tecnologia de Massachusetts), tornou-se a ferramenta ideal, criado para crianças, a partir de oito anos, visa a ensinar programação através de blocos de encaixe que se aproximam da vivência lúdica das crianças e não exigem conhecimentos prévios de programação, favorecendo o desenvolvimento de diversas habilidades e competências, conforme descreve Maloney, et. all, (2006):

- desenvolve competência para selecionar, criar e gerenciar múltiplas formas de mídia;

- desenvolve habilidades de comunicação, pois possibilita expressar-se de forma variada, crítica e criativa, através da linguagem da programação;

- desenvolve o raciocínio crítico e envolve os alunos na busca de soluções inovadoras para problemas inesperados, preparando-os para chegar a novas soluções para os novos desafios que surgem no processo.

- desenvolve a criatividade e a curiosidade intelectual, além do relacionamento interpessoal e o trabalho colaborativo.

$\mathrm{Na}$ busca do desenvolvimento dessas possibilidades, o Scratch tornou-se a linguagem de programação ideal. Amaral (2013, apud Rusk, Resnick e Maloney) relata a facilidade de programar utilizando o Scratch:

Criar um projeto Scratch requer pensar em uma ideia, em seguida, descobrir a forma de dividir o problema em etapas e implementá-las usando a programação em blocos. $\mathrm{O}$ ambiente ainda é projetado para que os alunos possam alterar dinamicamente partes do código e ver imediatamente os resultados; dessa forma, durante todo o processo de desenvolvimento de um projeto, os estudantes se engajam na experimentação e resolução de problemas de maneira interativa. (AMARAL, 2013)

De acordo com Amaral (2013), assim como não imaginamos nossa sociedade sem computador, não podemos conceber um cidadão que ignore os conhecimentos computacionais, sendo necessário desenvolver desde cedo habilidades para o uso destas tecnologias, que envolve dentre outras coisas, a capacidade de resolução de problemas, deixando de apenas fornecer respostas certas ou erradas para perguntas previamente estabelecidas.

Em Matemática, resolver problemas é uma proficiência que merece destaque, pois a todo momento, as pessoas deparam-se com a necessidade de solucionar e elaborar problemas, analisar dados, organizar, planejar e executar ações. As práticas cotidianas 
são cada vez mais problematizadas. Nos Parâmetros Curriculares Nacionais (PCN, 1998) podemos ler:

Resolver um problema pressupõe que o aluno:

- Elabore um ou vários procedimentos de resolução (como, por exemplo, realizar simulações, fazer tentativas, formular hipóteses);

- Compare seus resultados com os de outros alunos;

- Valide seus procedimentos.

Resolver um problema não se resume em compreender o que foi proposto e em dar respostas aplicando procedimentos adequados. Aprender a dar uma resposta correta, que tenha sentido, pode ser suficiente para que ela seja aceita e até seja convincente, mas não é garantia de apropriação do conhecimento envolvido. Além disso, é necessário desenvolver habilidades que permitam pôr à prova os resultados, testar seus efeitos, comparar diferentes caminhos, para obter a solução. Nessa forma de trabalho, o valor da resposta correta cede lugar ao valor do processo de resolução.

$\mathrm{O}$ fato de o aluno ser estimulado a questionar sua própria resposta, a questionar o problema, a transformar um dado problema numa fonte de novos problemas, evidencia uma concepção de ensino e aprendizagem não pela mera reprodução de conhecimentos, mas pela via da ação refletida que constrói conhecimentos (DANTE, 2009). Na programação com Scratch, está envolvida a resolução de problemas inesperados, que surgem no decorrer da programação, aliando os conceitos de matemática envolvidos.

\section{O Scratch no desenvolvimento de jogos digitais}

As habilidades fundamentais para a formação de um indivíduo atuante no século XXI envolvem saber utilizar seus conhecimentos em sua vida cotidiana, através de suas relações pessoais, interpessoais, social, cognitiva e criativa.

Diante desses desafios, passou-se a discutir, na educação, a integração das novas tecnologias ao currículo escolar, a aprendizagem baseada na solução de problemas e o desenvolvimento de habilidades para a criação de tecnologias e não apenas para um simples consumo.

Já não basta o simples consumo ou manuseio mecânico dos produtos disponíveis no mercado: esta sociedade necessita de indivíduos que sejam capazes de se deparar com a diversidade de situações do cotidiano e possam agir sobre elas, solucioná-las, transformá-las. Para tanto, há de se desenvolver competências e habilidades específicas para esta atuação. (SOBREIRA et. all, 2013)

Na obra "Games em educação", o professor João Mattar relata a importância de utilizar os recursos educacionais dos jogos digitais para o desenvolvimento de uma aprendizagem significativa diante de uma geração que nasce cercada por tecnologias.

$\mathrm{O}$ aprendizado necessita de motivação para um envolvimento intenso, o que é atingido pelos games, principalmente aqueles que pressupõem uma longa curva de aprendizado, mas não pela escola atual. A escola, tal como a conhecemos hoje, enfatiza o conhecimento separado da ação e da identidade." (MATTAR, 2010) 
Diante da necessidade de tornar a educação mais significativa e próxima do cotidiano dos nativos digitais, desenvolvendo a autoria e produção de tecnologias, o trabalho de criação de jogos digitais baseado no conteúdo curricular tornou-se uma solução para esse desafio. Nossos alunos já estão habituados a interagir com as mais diversas tecnologias, porém, a maioria deles não sabe como construir um jogo, criar novas tecnologias, ou seja, programar.

O Scratch viabiliza a realização desse trabalho nos anos iniciais do ensino fundamental I, conforme ressalta Sobreira (2013):

Pelo fato de o Scratch ser atraente e de fácil manuseio para o público infantil (a partir de oito anos de idade), o desenvolvimento da programação torna-se possível nesta faixa etária, além de divertida e significativa. Pode-se aliar o trabalho com a linguagem de programação no Scratch ao currículo escolar do Ensino Fundamental, trabalhando em uma perspectiva que busque desenvolver habilidades próprias para o cidadão do século XXI, o qual cria, gerencia uma diversidade de mídias, desenvolve seu raciocínio lógico na experimentação e resolução de problemas, além de compartilhar seus conhecimentos. (SOBREIRA et. all, 2013)

A criação de jogos digitais torna-se atraente para os alunos pois podem reproduzir seus games favoritos ou criar um jogo de sua autoria, tornando-se produtores de games. No Scratch, utilizando os blocos de sensores, operadores e variáveis, é possível reproduzir muitos comandos utilizados nos jogos digitais profissionais.

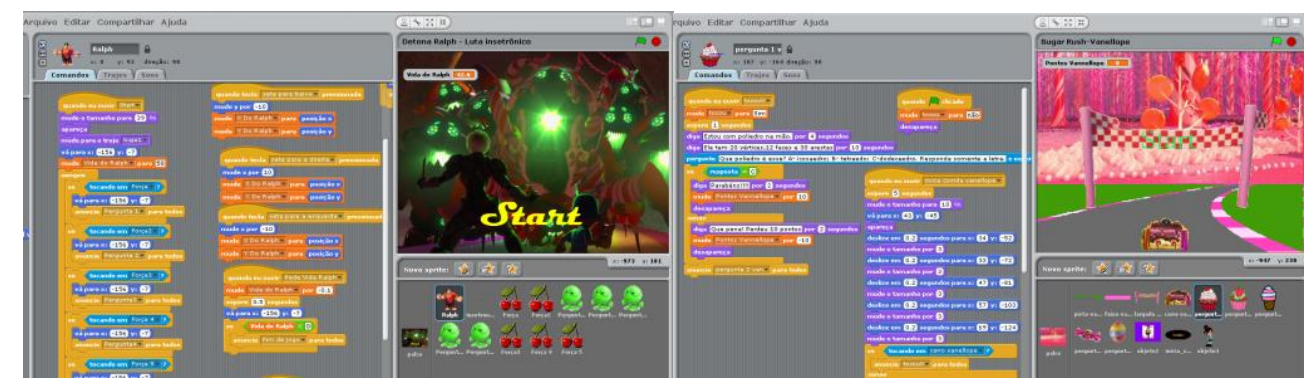

Figura 1. Programação dos jogos criados com o tema "Detona Ralph", utilizando sensores e operadores

\section{Desenvolvendo jogos digitais com alunos do ensino fundamental I}

A proposta de criação de um jogo digital envolveu quatro turmas do $5^{\circ}$ ano do ensino fundamental I, do Centro Educacional Pioneiro, no primeiro trimestre de 2015. Nessa proposta, os alunos escolheram o tema e desenvolveram colaborativamente jogos digitais com desafios de matemática, envolvendo os conteúdos abordados no trimestre.

Para a produção do jogo digital, além de resolver os problemas apresentados pela programação, os alunos foram desafiados a criar os problemas (desafios) para serem inseridos no contexto dos jogos digitais. Quando o aluno cria seus próprios textos de problemas, ele precisa organizar tudo que sabe e elaborar o texto, dando-lhe sentido e estrutura adequados para que possa comunicar o que pretende (CHICA, 2007).

Nesse processo, aproximam-se a língua materna e a matemática, as quais se complementam na produção de textos e permitem o desenvolvimento da linguagem 
específica. O aluno deixa, então, de ser um resolvedor para ser um propositor de problemas, vivenciando o controle sobre o texto e as ideias matemáticas.

\subsection{Objetivos do trabalho desenvolvido em sala de aula com auxílio dos recursos tecnológicos:}

Ao final do trabalho esperava-se que o aluno fosse capaz de:

- Produzir desafios de matemática exercendo a autoria;

- Criar roteiros e estratégias para produção de jogos digitais;

- Utilizar a programação para produzir jogos digitais;

- Desenvolver habilidades de argumentação, observação, dedução e espírito crítico

\subsection{Desenvolvimento do trabalho}

Para iniciar o trabalho que se desenvolveu de modo colaborativo envolvendo as 4 turmas do $5^{\circ}$ ano do ensino fundamental I, o primeiro desafio foi a escolha do tema do jogo. Cada turma criou várias sugestões as quais passaram por uma votação para escolher uma opção por classe, em seguida, houve uma votação geral para eleger o tema que mais agradou a todos os alunos das 4 turmas. Desta forma, ficou decidida a criação de um game no contexto do filme da Disney "Detona Ralph".

\begin{tabular}{|c|c|c|c|c|}
\hline Sugestōes: & \begin{tabular}{|l|} 
Votos \\
$52 A$ \\
\end{tabular} & $\begin{array}{l}\text { Volos } \\
558\end{array}$ & $\begin{array}{l}\text { Votos } \\
\text { sec }\end{array}$ & $\begin{array}{c}\text { Votos } \\
520\end{array}$ \\
\hline Detona Ralph & 15 & 8 & 11 & 3 \\
\hline Geometryc Dash & 0 & 0 & 0 & 0 \\
\hline Minions Rush & 1 & 8 & 4 & 5 \\
\hline Pac-Man & 5 & 5 & 0 & 7 \\
\hline
\end{tabular}

Figura 2. Imagem da tabela com os votos das 4 turmas para escolha do tema

Escolhido o tema geral, as turmas determinaram quais jogos dentro deste tema iriam criar; assim, decidiram entre as turmas que os $5^{\circ}$ s anos A e B ficariam com o Ralph "detonando" as janelas do prédio para o Félix consertar, o $5^{\circ} \mathrm{C}$ ficou com a Luta entre o Ralph e os vilões e o $5^{\circ}$ ano D, com a Corrida Doce, parte final do filme. Todos esses jogos com soluções através da resolução dos desafios de matemática.

Nossos alunos estão habituados a resolver exercícios, mas desta vez, fizemos a proposta para os alunos criarem os desafios de matemática para incluir nos jogos Detona Ralph. Primeiramente, reuniram-se em duplas para formular os problemas. Cada dupla, formulou dois desafios matemáticos. Os alunos puderam consultar o livro didático, ficha de atividades, internet (sites de charadas matemáticas, problemas de matemática) ou livro com desafios de matemática para auxiliar na construção dos desafios. A orientação foi para serem autores dos desafios. Alguns alunos tiveram dificuldades para criar e precisaram de orientação, resultando em alguns desafios baseados nas fontes citadas.

Foram utilizadas duas aulas de Matemática para elaboração dos desafios (as pesquisas na internet foram feitas em casa, os alunos trouxeram exemplos impressos com 
a fonte de pesquisa). Totalizaram 72 desafios, das quatro turmas. Parte da criação dos desafios é possível ser visualizado nas imagens a seguir:

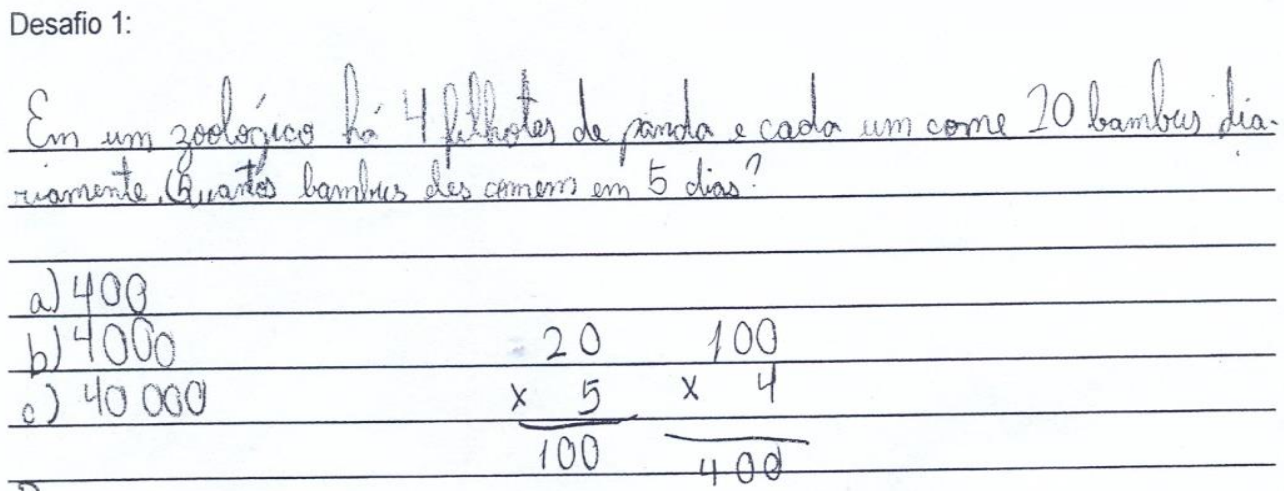

Figura 3. Desafio criado por um aluno do 5o ano A.

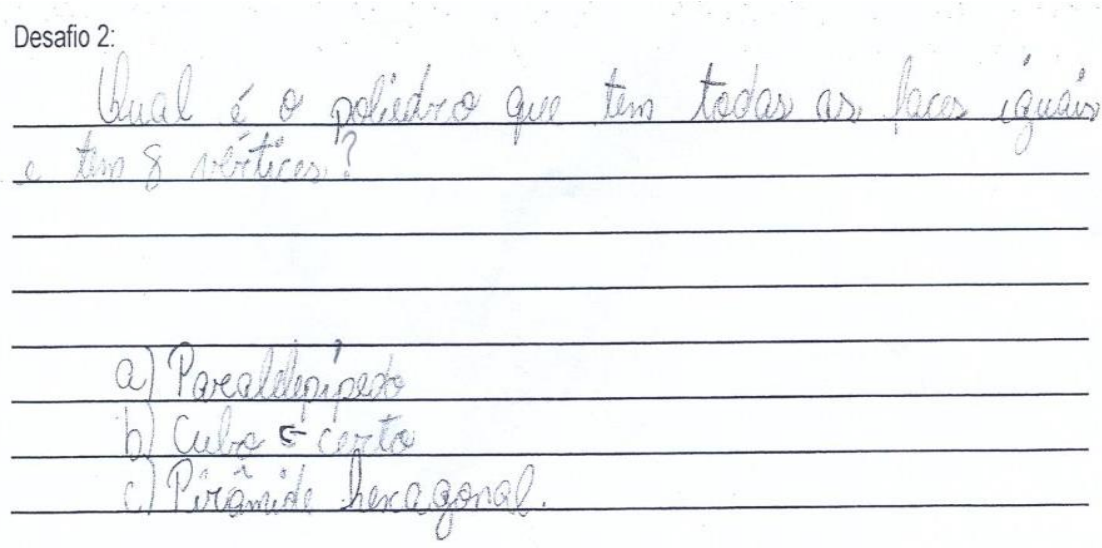

Figura 4. Desafio criado por um aluno do 5 ano D.

O propósito dos desafios nos jogos é estimular a capacidade inventiva e questionadora dos alunos, o que desenvolve na sala um clima de interação, comunicação de ideias, estabelecimento de relações e aplicação de conceitos. Conforme Chica (2007), queremos que nossos alunos sejam agentes de suas aprendizagens, que se tornem leitores e escritores em matemática, que produzam algo que tenha sentido e utilidade para eles.

Depois da elaboração dos desafios, os alunos iniciaram a programação dos jogos utilizando o Scratch. Para isto, os alunos pesquisaram outros jogos criados no Scratch, com desafios parecidos com os que escolheram, de modo que pudessem observar a programação existente obtendo parâmetros para criar sua própria programação. Na comunidade oficial do Scratch (https://scratch.mit.edu/), onde diversos usuários compartilham suas programações, é uma rica fonte de pesquisa para as crianças que começam a desenvolver programações.

Para a programação do jogo da "Corrida Doce", do $5^{\circ}$ ano $\mathrm{D}$, os alunos encontraram exemplos de jogos de corrida com programações avançadas que dificultavam o entendimento de todas as variáveis. Para que fosse possível efetivar a 
programação deste jogo, os alunos reuniram-se em grupo e, com a ajuda das professoras, criaram uma programação com comandos mais simples, dentro das suas possibilidades de compreensão. Para os demais jogos, a diversidade de exemplos pesquisados facilitou a criação de programações variadas, onde cada dupla ou grupo pode criar com mais autonomia.

Para a ilustração utilizaram imagens e personagens do filme "Detona Ralph" disponíveis na internet. Cada turma decidiu como seria a construção do jogo. O $5^{\circ} \mathrm{A}$ e B optaram por cada dupla criar um desafio para cada janela quebrada, juntando todos em um único jogo criado colaborativamente entre todas as duplas da classe. Ao passo que, as turmas $5^{\circ} \mathrm{C}$ e $\mathrm{D}$ optaram por cada grupo de alunos criar um jogo diferente no mesmo tema, sendo assim, no $5^{\circ} \mathrm{C}$ eles se dividiram em 3 grupos criando 3 jogos de luta e o $5^{\circ} \mathrm{D}$ criou 3 jogos de corrida, todos com diferentes personagens do filme.

\section{Resultados e discussões}

Os alunos conseguiram criar os roteiros e as estratégias dos jogos através das diversas discussões, com argumentos individuais, que resultaram em tomadas de decisões em grupo, favorecendo a produção coletiva. Desenvolveram autonomia na programação do jogo ao longo do projeto, conseguindo observar e deduzir os erros para modificar as programações, ou seja, resolveram problemas inesperados que surgiram no decorrer do processo.

Os recursos tecnológicos foram fundamentais para o desenvolvimento dos jogos, onde os alunos puderam programar e desenvolver habilidades de autoria e protagonismo, compartilhando suas produções e abrindo novas oportunidades de comunicação.

Em Matemática, o trabalho com formulação de problemas exigiu paciência, pois tal atividade demandou muitas idas e vindas, cabendo ao professor orientar os alunos sem atropelar o processo de criação. Alguns estudantes tiveram dificuldades na formulação, por isso foi necessário retomar com outras propostas, o que demandou, mais do que apenas algumas aulas. Esse trabalho, deve ser diversificado, constante e valorizado.

A utilização do Scratch como recurso pedagógico propiciou o envolvimento dos alunos no desenvolvimento do conteúdo curricular. A programação com Scratch promove o desenvolvimento de conceitos matemáticos, pois envolve conhecimentos de localização no plano cartesiano (posição x, posição y), a lógica das variáveis e o uso de condições (se e senão).

Neste trabalho, foram estudados os problemas que envolvem as quatro operações, sequências de números, sistema de numeração, conceitos de poliedros e corpos redondos. Integrar os desafios com os jogos digitais criados no Scratch, contribuiu para o desenvolvimento da capacidade de resolução de problemas e estimulou a (re)formulação de problemas de um modo significativo.

A finalização do trabalho ocorreu no Scratch Day, onde os alunos socializaram suas produções e publicaram na comunidade oficial do Scratch: https://scratch.mit.edu/studios/1200578/. Os pais participaram valorizando a produção dos alunos e a estratégia de integrar os jogos à educação, aliando a vivência cotidiana ao currículo escolar. 


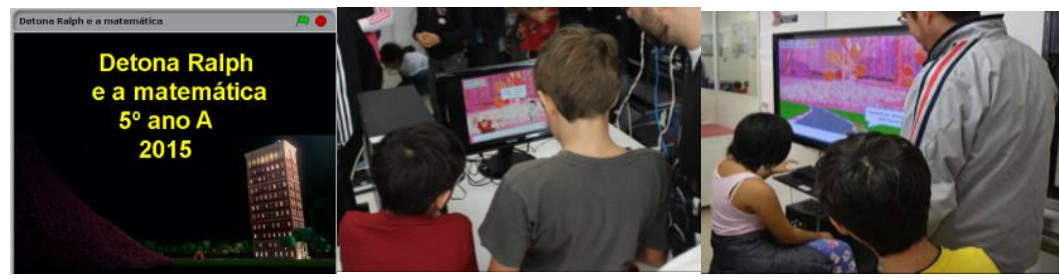

Figura 5. Tela do jogo e fotos da socialização no Scratch Day.

\section{Conclusões e continuidade do trabalho}

A criação de jogos digitais integrados com o currículo, foi uma forma de aproveitar o poder de motivação dos jogos, construindo assim, uma fronteira entre diversão e aprendizagem. Os alunos tiveram a oportunidade de refletir sobre a criação de conteúdos, ao invés de apenas utilizar, responder, resolver ou jogar o que já está pronto. Após a criação, a vontade de jogar, testar e compartilhar suas produções era muito grande, isso porque não criaram apenas um objeto de estudo, mas um jogo divertido e instigante ao mesmo tempo.

Esta prática de criação e produção é um exercício que precisa de mais momentos para apropriação. No início, os participantes não apresentaram autonomia, necessitando observar modelos prontos para criar, onde verificamos a necessidade de uma continuidade dessa prática, de modo que os alunos possam desenvolver autonomia e criar partindo de suas próprias ideias.

Faz-se necessário o desenvolvimento de estratégias para melhor avaliar o avanço na aprendizagem dos alunos relacionadas ao conhecimento de programação, o que será possível com a programação de novos jogos para observar a autonomia no uso dos códigos computacionais.

Para o professor, a formulação de problemas com a interação dos jogos digitais, é um instrumento de avaliação, pois fornece indícios sobre o domínio dos alunos em relação aos conceitos matemáticos, além de permitir que se observe a capacidade de criação em grupo e os relacionamentos interpessoais.

Através dos dados obtidos com este trabalho, o professor pode planejar as novas ações de ensino que deseja desenvolver com seus alunos nos trimestres seguintes.

\section{Referências}

Andrade, M.; Silva, C.; Oliveira, T. Desenvolvendo games e aprendendo matemática utilizando o Scratch. In: Simpósio Brasileiro de Jogos e Entretenimento Digital. São Paulo, 2013. Proceedings do XII SBGames: Culture Track - Short Papers. São Paulo: SBGames, 2013, p.260-263. DEisponível em: < http://www.sbgames.org/sbgames2013/proceedings/cultura/Culture-5_short.pdf $>$ Acesso em 12 de maio de 2015.

Amaral, Haroldo José Costa do; França, Rozelma Soares de. Proposta Metodológica de Ensino e Avaliação para o Desenvolvimento do Pensamento Computacional com o Uso do Scratch. Anais do II CBIE e XIX WIE, 2013. Disponível em: $<$ http://www.brie.org/pub/index.php/wie/article/view/2646> Acesso em 12 de maio de 2015. 
Costa, Fernando Albuquerque. O Currículo e o Digital. Onde está o elo mais fraco? [Edição em CD-Rom]. In P. Dias, C. V. Freitas, B. Silva, A. Osório \& A. Ramos (Eds.), Atas da $\mathrm{V}$ Conferência Internacional de Tecnologias de Informação e Comunicação na Educação, Challenges 2007. Braga: Centro de Competência da Universidade do Minho, 2007. Páginas: 274-284.

Chica, Cristiane H. Por que formular problemas? In: Smole, Kátia Stocco; Diniz, Maria Ignez (organizadoras). Ler, escrever e resolver problemas: habilidades básicas para aprender matemática. Porto Alegre: Artmed, 2007.

Dante, Luiz Roberto. Formulação e resolução de problemas de matemática: teoria e prática. São Paulo: Ática, 2009.

Gomes, Wesckley Faria; Louzada, Carolina Santana; Nunes, Maria Augusta Silveira Netto; Salgueiro, Edilayne Meneses; Andrade, Beatriz Trinchão. Incentivando meninas do ensino médio à área de Ciência da Computação usando o Scratch como ferramenta. Anais do III CBIE e XX WIE, 2014. Disponível em: <http://www.brie.org/pub/index.php/wie/article/view/3104> Acesso em 12 de maio de 2015.

Mattar, João. Games em educação: como os nativos digitais aprendem. São Paulo: Pearson Prentice Hall, 2010.

Sobreira, Elaine Silva Rocha; Takinami, Olga Kikue; Santos, Verônica Gomes dos. Programando, Criando e Inovando com o Scratch: em busca da formação do cidadão do século XXI. Anais da JAIE, 2013. Disponível em <http://brie.org/pub/index.php/pie/article/view/2592/2248>. Acesso em 12 de maio de 2015.

Maloney, John; Rusk, Natalie; Resnick, Mitchel. 21st Century Learning Skills. Lifelong Kindergarten Group MIT Media Laboratory, 2006. Disponível em: $<\mathrm{http}: / / 1 \mathrm{k} . \mathrm{media} \cdot \mathrm{mit}$. edu/papers/scratch-21st-century.pdf $>$. Acesso em 18 de maio de 2015 .

Mota, Fernanda P.; Ribeiro, Nathan F. A.; Emmendorfer, Leonardo; Butzen, Paulo; Machado, Karina S.; Adamatti, Diana F. Desenvolvendo o Raciocínio Lógico no Ensino Médio: uma proposta utilizando a ferramenta Scratch. Anais do III CBIE e XXV SBIE, 2014. Disponível em: $<$ http://www.brie.org/pub/index.php/sbie/article/view/2964> Acesso em 18 de maio de 2015.

Parâmetros Curriculares Nacionais - PCN. Terceiro e quarto ciclos do ensino fundamental: matemática. Brasília: Ministério da Educação e do Desporto, 1998. 